\title{
Several Psychological Theories and Methods to Persuade and Educate the Followers of Heretic Sects
}

\author{
Xu Bibo, Yan Meifu, Liu Qizhen \\ Hubei University, Wuhan, China
}

\begin{abstract}
How to let the persons who join heretic sects wrongly break away from the cults is regarded as a difficult problem in the world. This authors sum up the four kinds of effective methods through their over 10 years' experiences that they had persuaded and educated the followers of heretic sects through psychology principles in mainland China. The methods include cognitive disorder, debate method, psychological hint method and psychological diagnosis method.
\end{abstract}

Keywords: heretic sects, cognitive disorder, debate method, psychological hint

When a person joins a cult mistakenly, it is an extremely hard mission to separate him or her from the heretic sect when he or she has been brainwashed. It is true for the cult followers in mainland China and is also for the ones in different countries in the world, especially the followers who believe in Falun Gong movement. Therefore, what kinds of reasons make the followers unable to break away from the manipulation of the heresy? The experiences have proved that it is mainly psychological. So, after years' exploration, we have summed up 19 kinds of psychological relief methods of persuasion and education, and four ones are introduced in this paper.

\section{Cognitive Disorder}

This paper tries to take the followers of Falun Gong movement for an example. They turn a deaf or laugh at contemptuously to peoples' persuasion and education. In their vies, what you say is the low-level opinions of ordinary people and people cannot understand their beliefs and truths. These followers have formed such mental set: the words of the mentor are absolutely right and the reason that people cannot understand is your low levels. To let them go out of the mental circle constructed by Falun Gong needs the truth as steel to cause their cognitive disorders. The below is an example.

\section{Case 1: Change Cognition with Real Facts}

Ms Gao, female and 45 years old, has received the education of technical secondary school and is a Chinese Communist Party member, as well as a firm believer and a practitioner of Falun Gong. She left the cult through several real facts, from which she realized that Li Hongzhi is not honest and cheated others, so the her wake-up was achieved by her cognitive disorder. The first was that Li Hongzhi said the April 25 Event had nothing to do him, when he was in the trip from the United States to Australia, and he totally had no idea of it.

Xu Bibo, associate professor, Director of Psychology Department, Hubei University.

Yan Meifu, professor, Psychology Department, Hubei University.

Liu Qizhen, professor, Psychology Department, Hubei University. 
Ms Gao thought it could tell that Li Hongzhi was lying, because there were numerous little bodies almost everywhere. The bodies followed each follower all the time and he knew clearly what his disciples did. But, there were so many disciples gathering in Sea Palaces. Why did Li Hongzhi not know? His words were fake obviously.

The second event was the report on Minghui Website that Peng Min was beaten to death by the policeman in mainland China. When she heard this forged report, she thought the Chinese Communist Party was extreme bad and believed it was not right to treat the believers of Falun Gong in such a cruel way. In her eyes, the website was the representative of Li Hongzhi in Mainland China just like the People's Daily as the mouthpiece of the Communist Party. So, she believed it highly. But when Lu Jianhong told her that Peng Min was not murdered by the policeman, who has spent a long time with the dead man. The fact was that he hit the wall and broke his skull, the policemen of the mainland China were afraid of his death and being framed by Falun Gong, so they sent him to hospital immediately. At last, he was died of invalid cure at last. Cheng Jianhong and Peng Min were best friends, the speeches of Cheng Jianhong was believable. So, Ms Gao found that Li Hongzhi was not sincere and honest and cheated other, was a cunning man. Based on it as a breakthrough, she didn't believe Falun Gong any longer.

\section{Debate Method}

Among the large number of followers of Falun Gong, some are good at debate and arguing with persuaders. These people all think highly of themselves and believe they have the truth. They firmly believe that the truth, goodness and tolerance of Falun Gong and other beliefs, which are not overthrown by anyone in the universe. They extremely despised their debate rivals subconsciously and felt confident to face the debate opponents. For such those followers, the regular persuasion has almost zero effect on them. In such condition, debate method is more suitable for them.

The so-called debate method means that the persuaders have the face-to-face, equal and open argument with cult believers in some questions. While the referee is present, the both parties don't fight badly, don't push each other, don't pester each other endlessly, strictly comply with rules of debate and take the principle of persuasion peacefully until one party abandons its ideas and is convinced by another one. If the wrong ideas are defected one by one in repeated arguments, the mind of followers will change in quality in the accumulation of quantity. So, her divorce with Falun Gong will come soon.

However, to make the debate valid, the both parties should decide the debate rules and set up the justice of the referees argue recognized by both parties, the methods and skills of debate are a lot, the Socratic polemics (also known as maieutic Forensics) is regarded as a better choice.

\section{Case 2: The Dialogue Between a Persuader and a Follower of Galun Gong}

A female follower of Falun Gong built the dam with some villagers. The site had a landslide and the soil buried her both legs, and she could not move at all. The villages rushed to rescue her and dog out some mud. One of her leg was pulled out, when the villagers were about to help her with another leg, she suddenly thought that she was a disciple of Li Hongzhi. When she was in danger, she spoke one sentence that the Falun Gong Law was good and the truth, goodness and tolerance was good, and the miracle would show up. So she refused the rescue provided by the villagers, and tried the rule. She repeated the sentences again and again. She used the leg outside of mud hardly and pulled the leg in soil. The leg was pulled out unexpectedly, so she believed the Falun Gong was amazing. The small bodies of Li Hongzhi really protected her from dangers and bad lucks. 
Persuader: Why do you think you will be out of danger in the soil?

Follower of Falun Gong: Thanks to the Master and his power is endless, his small bodies will protect his disciples. Whenever we are and what disasters we will face, we are all free from the dangers.

Persuader: When Li Hongzhi was in the foreign country, did he know that there would have a landslide here?

Follower of Falun Gong: Yes, of course, his small bodies are with each follower.

Persuader: Really? Have you ever seen the small body of Li Hongzhi in person?

Follower of Falun Gong: No, I didn't. But when I shouted out the sentence, I felt that his body helped me pull another leg.

Persuader: Could you please tell me how many people were buried in site? Were you the only buried person? Weren’t they building with you?

Follower of Falun Gong: When the slide happened, I was the only person in the soil. There were some people, but they were not disciples of Li Hongzhi.

Persuader: How it could be? Why are you buried, rather than others when the landslide happened?

Follower of Falun Gong: why?

Persuader: Because they are normal people and have no protection of Master Li. You are a disciple, with his protection, how could you were buried in the soil?! When the land slide happened, where was your master? Where was his small body? You said he is the Lord Buddha with infinite forces. He knows everything in air, earth, past and future things and is in charge of everything. Why did he instruct you to hide or stop the landslide if he knew you were in there?

Followers of Falun Gong: I...

\section{Psychological Hint Method}

Everyone implies. Studies have shown that the cult followers or believers have higher hints than normal people, among which female one is higher than the male one. The role of psychological hints of many people are caught by heretic sects, which gives us a suggestion that cults use psychological hints to draw people and make them become the firm followers. Why can we use the hint to save them? So we made exploration in this aspect and had a good results. The below is two examples of psychological hints.

\section{Environmental Hint}

In a tall building, it happened there were more than 10 cult followers, which might cause by the proximity of interpersonal attraction. A group of volunteers persuaded these believers intensively. In the period, when each follower finally announced the breakup with the cult after being hardly persuaded and educated, a small party will be held in his or her house. Volunteers, cult followers and their families all sung songs together, related persons came to celebrate. The cheering up words and laughter were from the house. At the moment, the victory environment will fill in the whole building. When the followers heard the familiar songs and laughter, they would know another person separated from the cult. In the days of intensive education and persuasion, such songs and laughter would be happened several times a day, sometimes at night. Don't think it was just for victory and celebration, it had an more important meaning that they gave the hints to the followers who firmly believed the cult: You cannot adhere in the long term, other followers like you were persuaded, aren't they? The facts have proved that, in such psychological hints, some followers left the cult without much struggles.

\section{Typical Hint}

Focusing on the favorable forces in the education and persuasion, first hold the followers who are poisoned most and most stubborn, persuade and convince the followers with biggest influences and most representative, use psychological hints to persuade.

A follower of Falun Gong who was disconnected with the cult said to the persuading volunteers that he was relieved when he saw Wang in the list of persuaded cult followers. Everyone knew Wang was the best 
learner of Falun Gong and his position was firmest among other the followers. So he thought if the person could insist, he can hold on. He waited to see what kinds of methods the volunteers use to persuade him. He never thought the person was successfully persuaded within a few days. He could not believe at first, when he found it was true, so his mind was crushed down. He always wondered what the volunteers used to convince people like Wang, so a sense of admiring feeling came out naturally. So he began to wonder whether he could adhere or not and where there was a reason that he could persist in. After one sentence of volunteers, he began to swing. Obviously, the persuasion of Wang was a wordless hint for him. Wang was such a firm believer and follower, he was educated to left the cult. The volunteers must have methods to let him disconnect with Falun Gong.

\section{Psychological Diagnosis Method}

While talking with the cult followers who cannot left the cult, volunteers shall start from the perspective of spiritual medicine and abnormal psychology, some followers may suffer from serious mental disorders or severe psychopath, who cannot be persuaded out of the cult through persuasion and education. Different from the typical severe mental illness or abnormal psychology in psychiatry and abnormal psychology, although their symptoms, severity and duration of disease have met the diagnosis standards of mental disorders , their speeches, deeds and behaviors are heretic. They are usually regarded as the stubborn cult followers and believers after the invalid persuasion and education. The corrective ways to treat such followers are:

First, according to followers' unified principle of the subjective and the objective world, the internal coordination principle of mental activities, personality relative stability principle, diagnose their self-conscience on their diseases and check whether they have the psychiatric symptoms like delusions, hallucinations, confusion and other of cardiac diagnosis, and judge whether they suffer from severe mental illness. If they have the mental disorders, verbal persuasion and education is invalid, and they should be treated medically.

Second, for the followers who have minor mental disease in the non-onset period, they can receive persuasion and education while having the logic minds and understanding ability and having medical treatment. For those who have some kinds of psychological disorder like hysteria, they can receive the same treatment.

\section{Case 3: She Is a Woman Who Suffers from Schizophrenic}

$\mathrm{Ms} \mathrm{Wu}$, female and 53 years old, has the education of middle school and is unemployed, living in the city. She has been exercised Falun Gong for five years. After persuasion and education, she expressed that she would break away from the cult and asked someone to write the materials in paper. But later, she announced that the materials written before was invalid and she could not separate from Falun Gong and her master. She told the persuaders that her 81-year-old mother was the daughter of Li Hongzhi, and she has been the wife of Li Hongzhi for 3 lives. Li Hongzhi told her for many times that she had connection with him and her two children were kids of Li Hongzhi and she. After she announced that she could not leave Falun Gong and her master, she often said she was sorry for him and she could not betray him or something like these, her mood was very upset. She felt being monitored all the time and something really bad would happen to her. In a conversation with a volunteer, she first stood up humbly and answered what she was asked. But in the middle of conversation, she turned very nervous and panic, her body began to shake, and she had asked to stop the talk for several times. She said her master was behind her back and he was hardly blaming her betrayal. Then she left the room gingerly and hastily to escape from her master, while passing several rooms, she looked back with a extremely 
panic manner. After more than one year's persuasion and education, she still could not disconnect with Falun Gong.

Through observation, Ms Wu had a clear mind, expect a large number of speeches about Falun Gong, she also had the phonism, heteroptics, beziehungswahn, delusion of persecution, delusion of self-accusation, paralogi thinking and other psychotic symptoms, she was diagnosed as schizophrenia caused by Falun Gong and she needs to medical treatment first and then the persuasion and education.

\section{References}

David, M. (2006). Social psychology. Beijing: People’s Posts and Telecommunications Publishing House.

Guo, Y. Y., \& Wang, W. (2007). Psychological guidance. Wuhan: Central China Normal University Press.

Guo, N. F. (2005). Psychological consultation teacher. Nationalities Publishing House.

Huang, X. T. (1991). Introduction of psychology. Beijing: People’s Education Press.

Richard, G., \& Philip, Z. (2003). Psychology and life. Beijing: People’s Posts and Telecommunications Publishing House.

Shi, R. H. (1998). Social psychology. Hangzhou: Zhejiang Education Publishing House.

Su, H. (2006). Mystery of secret belief. Nanjing: Jiangsu People’s Publishing House.

Social Issues Forum Editorial Board. (2001). On cults. Nanning: Guangxi People’s Publishing House.

Social Issues Forum Editorial Board. (2005). Second comment on cults. Nanning: Guangxi People’s Publishing House.

Wang, Z. C. (2002). Psychiatry. Beijing: People’s Medical Publishing House.

Zhang, C. X. (1994). Modern psychology. Shanghai: Shanghai People’s Publishing House. 